07

\title{
Релаксация напряжений
}

в InGaAsP/InP-гетероструктурах

для преобразователей лазерного

излучения с длиной волны $1064 \mathrm{~nm}$

(C) А.Е. Маричев, Р.В. Левин, А.Б. Гордеева, Г.С. Гагис,

В.И. Кучинский, Б.В. Пушный, Н.Д. Прасолов, Н.М. Шмидт

Физико-технический институт им. А.Ф. Иоффре РАН, Санкт-Петербург

๑ E-mail: Natalia.Shmidt@mail.ioffe.ru

Поступило в Редакцию 18 августа 2016 г.

Исследованы особенности релаксации механических напряжений в $\mathrm{InGaAsP/InP-гетероструктурах,} \mathrm{являющихся} \mathrm{основой} \mathrm{для} \mathrm{преобразователей} \mathrm{ла-}$ зерного излучения с длиной волны $1064 \mathrm{~nm}$. Показано, что релаксация механических напряжений путем образования упорядоченного рельефа на поверхности слоев твердого раствора InGaAsP/InP-гетероструктур с составом твердого раствора по индию до $80 \%$ позволяет уменьшить вероятность спинодального распада твердого раствора, повысить на порядок интенсивность фотолюминесценции твердого раствора и увеличить эффективность преобразования лазерного излучения.

DOI: 10.21883/PJTF.2017.02.44180.16463

Полупроводниковые InGaAsP/InP-гетероструктуры с твердым раствором InGaAsP, изопериодным с InP и шириной запрещенной зоны $1.0-1.2 \mathrm{eV}(300 \mathrm{~K})$, с содержанием индия до 80\%, являются хорошим кандидатом для создания преобразователей лазерного излучения с длиной волны $1064 \mathrm{~nm}$, обеспечивающей минимальные потери при 
прохождении излучения в земной атмосфере. Одно из применений таких преобразователей лазерного излучения - передача электрической энергии на расстояние. Концепция передачи электрической энергии на расстояние без проводов была предложена более 100 лет назад Николя Тесла. Однако только в XXI веке, благодаря созданию мощных лазеров, она приобрела практическое значение и началось создание систем передачи энергии, в том числе в земной атмосфере и в космическом пространстве [1-3]. Одно из основных требований к преобразователям в системах передачи энергии - максимальная эффективность преобразования излучения. При разработке технологии получения твердых растворов с содержанием индия до $80 \%$, на длину волны $1064 \mathrm{~nm}$ выяснилось, что такие составы попадают в область спинодального распада твердого раствора [4]. В этом случае возрастает вероятность образования в активной области фаз с непрерывно меняющимся составом, что неизбежно приводит к снижению эффективности преобразования излучения в электрическую энергию. Известно, что управление степенью рассогласования параметров решетки твердого раствора активной области и характером релаксации механических напряжений в гетероструктуре [4-6] позволяет избежать спинодального распада твердого раствора. Исходя из этого, в работе изучалось влияние толщины слоя InGaAsP твердого раствора, степени рассогласования его параметров решетки относительно InP на характер релаксации механических напряжений в слоях твердого раствора InGaAsP/InPгетероструктур, а также интенсивность фотолюминесценции на длине волны $1064 \mathrm{~nm}$.

На основе ранее проведенного расчета в рамках модели квазирегулярных растворов [6,7] и моделей, учитывающих дельта-параметры, были определены границы области спинодального распада твердых растворов InGaAsP, изопериодные с InP при температурах роста $600^{\circ} \mathrm{C}[8,9]$. При этой температуре были выращены InGaAsP-слои с шириной запрещенной зоны $1.0-1.2 \mathrm{eV}$ и InGaAsP/InP-гетероструктуры методом эпитаксии из металлоорганических соединений на подложках InP $n$-типа проводимости, легированных теллуром с концентрацией носителей $(1-5) \cdot 10^{18} \mathrm{~cm}^{-3}$ и разоориентированных на $4^{\circ}$ относительно плоскости (100). Рост слоев твердого раствора проводился на буферных слояx InP толщиной $1 \mu \mathrm{m}$ на установке AIXTRON AIX-200, при давлении $100 \mathrm{mbar}$, в потоке очищенного водорода, с точкой росы не хуже $-100^{\circ} \mathrm{C}$ и при скорости подачи водорода в реактор $51 / \mathrm{min}$.

Письма в ЖТФ, 2017, том 43, вып. 2 

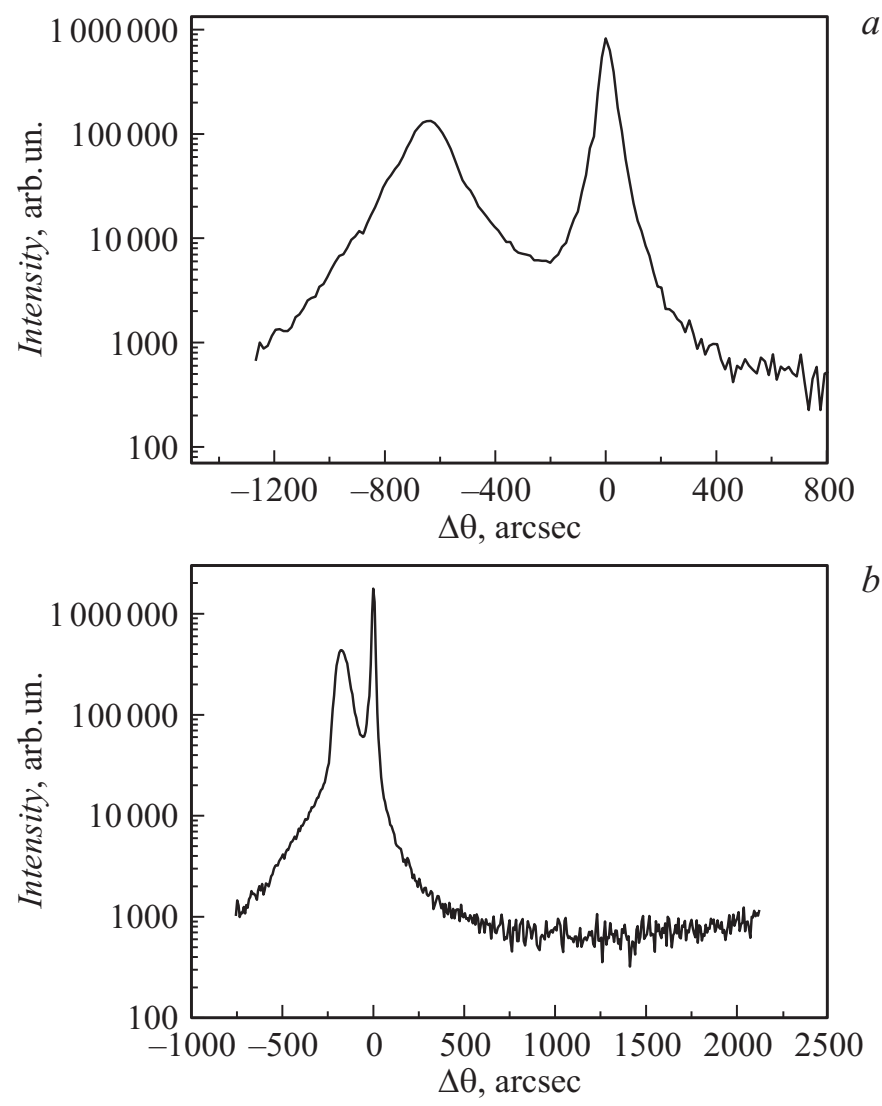

Рис. 1. Кривые качания твердых растворов InGaAsP с разным рассогласованием параметров решетки: $a-1.5 \cdot 10^{-2}, b-3.88 \cdot 10^{-3}$.

B качестве источников $\mathrm{Ga}$ и In применялись металлоорганические соединения, соответственно TEGa-триэтилгаллий и TMIn-триметилиндий, а в качестве источников $\mathrm{AsH}_{3}$ и $\mathrm{PH}_{3}$ использовались гидриды $\mathrm{AsH}_{3}$-арсин и $\mathrm{PH}_{3}$-фосфин. Толщина слоев твердого раствора в гетероструктурах варьировалась от 50 до $1000 \mathrm{~nm}$. Кроме того, в небольших пределах в слоях толщиной $1000 \mathrm{~nm}$ варьировался состав твердого

Письма в ЖТФ, 2017, том 43, вып. 2 




$x: 10.0 \mu \mathrm{m}$

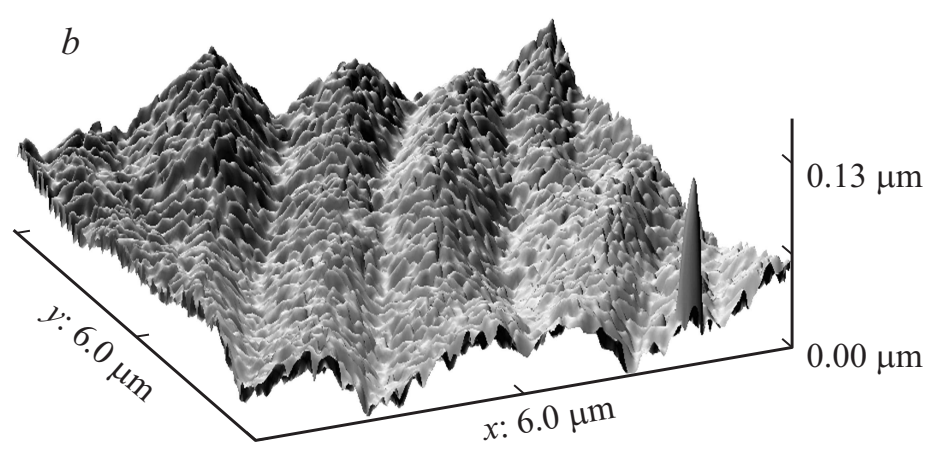

Рис. 2. Изображение в атомно-силовом микроскопе морфологии поверхностей твердого раствора $\operatorname{In}_{0.8} \mathrm{Ga}_{0.2} \mathrm{As}_{0.46} \mathrm{P}_{0.54} / \mathrm{InP}$-гетероструктур с разной толщиной слоя и рельефом: $a-50 \mathrm{~nm}$, без крупного упорядоченного рельефа; $b-$ $1000 \mathrm{~nm}$, упорядоченный рельеф; $c$ - профиль рельефа с участками нарушения упорядоченности.

раствора от $\operatorname{In}_{0.8} \mathrm{Ga}_{0.2} \mathrm{As}_{0.46} \mathrm{P}_{0.54}$ до $\mathrm{In}_{0.879} \mathrm{Ga}_{0.121} \mathrm{As}_{0.28} \mathrm{P}_{0.72}$. При этом контролировалось рассогласование параметров кристаллической решетки методами рентгеновской дифрактометрии. Контроль морфологии поверхности гетероструктур осуществлялся методами атомно-силовой микроскопии. Оптические свойства выращенных слоев твердого раствоpa InGaAsP/InP-гетероструктур исследовались методами фотолюминесценции и спектроскопии анизотропного отражения.

Письма в ЖТФ, 2017, том 43, вып. 2 




Рис. 2 (продолжение).

Выяснено, что в слоях твердого раствора толщиной $1000 \mathrm{~nm}$ с содержанием индия до 83 и $88 \%$ наблюдается рассогласование параметров кристаллической решетки слоев InGaAsP относительно подложки $\operatorname{InP}$ (отношение $\Delta a / a$, где $a-$ постоянная кристаллической решетки) от $2 \cdot 10^{-3}$ до $1.5 \cdot 10^{-2}$. При этом наблюдается фазовый распад твердого раствора, что хорошо видно на представленных на рис. 1 кривых качания этих твердых растворов. По данным спектроскопии анизотропного отражения в этих слоях присутствуют области, обогащенные GaAs и InAs. Присутствие таких областей и фазовый распад не наблюдаются в слоях $\operatorname{In}_{0.8} \mathrm{Ga}_{0.2} \mathrm{As}_{0.46} \mathrm{P}_{0.54}$ с рассогласованием параметра решетки относительно $\mathrm{InP}$ меньше $2 \cdot 10^{-3}$. Влияние толщины твердого раствора с таким составом и рассогласованием на характер релаксации механических напряжений исследовалось в диапазоне толщин 50-1000 nm. Исходя из того, что в тонких слоях напряжения могут частично релаксировать путем образования рельефа на поверхности [10], проводился контроль морфологии поверхности слоев в атомно-силовом микроскопе. При толщине $50 \mathrm{~nm}$ упорядочен-

Письма в ЖТФ, 2017, том 43, вып. 2 


\begin{tabular}{c|c|c|c|c|c}
\hline Толщина, $\mathrm{nm}$ & $h, \mathrm{~nm}$ & $L_{0}, \mu \mathrm{m}$ & $L_{d}, \mu \mathrm{m}$ & $\sigma, \mathrm{dyn} \cdot \mathrm{cm}^{-2}$ & ФЛ, r. u. \\
\hline 1000 & 63 & 1.3 & 1.3 & $1.4 \cdot 10^{9}$ & $1.2 \cdot 10^{5}$ \\
500 & 31 & 1.2 & 1.3 & $3.4 \cdot 10^{8}$ & $1.589 \cdot 10^{4}$ \\
200 & Неупорядоченная & & & меньше $10^{8}$ & 2722 \\
50 & То же & & & & 601.9 \\
1000 & $"$ & & & & 694.3 \\
1000 & $"$ & & & & 1875
\end{tabular}

ного рельефа поверхности не наблюдается (рис. 2,a). Выяснено, что начиная с толщины $200 \mathrm{~nm}$ происходит эволюция рельефа от слабо упорядоченного к ярко выраженному упорядоченному рельефу при толщине твердого раствора $1000 \mathrm{~nm}$ (рис. 2, b). Профиль рельефа слоя, содержащего области с нарушенной упорядоченностью, полученный атомно-силовой микроскопией, представлен на рис. 2,c. Известное соотношение [11] позволяет определить величину механических напряжений, сброшенных путем образования рельефа:

$$
\sigma=2 G h^{2} / L_{d} L_{0}
$$

где $\sigma-$ напряжения, $G-$ модуль сдвига, $h-$ высота гребня, $L_{d}-$ расстояние между гребнями, $L_{0}-$ ширина у основания гребня. Значения $h, L_{d}$ и $L_{0}$ определены из профиля рельефа и приведены в таблице.

Среднее значение модуля сдвига определялось из справочных данных сайта ФТИ, $G_{\text {mean }} \sim 2.8 \cdot 10^{11} \mathrm{dyn} \cdot \mathrm{cm}^{-2}$ из следующих значений модулей сдвига: $G_{\mathrm{GaAs}}=3.28 \cdot 10^{11} \mathrm{dyn} \cdot \mathrm{cm}^{-2}, G_{\mathrm{GaP}}=3.92 \cdot 10^{11} \mathrm{dyn} \cdot \mathrm{cm}^{-2}$, $G_{\mathrm{InP}}=2.25 \cdot 10^{11} \mathrm{dyn} \cdot \mathrm{cm}^{-2}, G_{\mathrm{InAs}}=1.9 \cdot 10^{11} \mathrm{dyn} \cdot \mathrm{cm}^{-2}$. Оценки напряжений, сброшенных за счет образования рельефа, приведены в таблице. Максимальные напряжения $1.4 \cdot 10^{9} \mathrm{dyn} \cdot \mathrm{cm}^{-2}$ сброшены в слоях толщиной $1000 \mathrm{~nm}$ за счет образования хорошо развитого упорядоченного рельефа рис. 2, $b$. Этот результат подтверждается также данными спектроскопии анизотропного отражения. Значения напряжений, сброшенных за счет образования рельефа, уменьшаются по мере выполаживания гребней рельефа и нарушения его упорядоченности. При толщине $200 \mathrm{~nm}$ из-за неупорядоченного рельефа очень приближенные оценки дают величину напряжений меньше $10^{8} \mathrm{dyn} \cdot \mathrm{cm}^{-2}$. Фотолюминесценция (ФЛ) наблюдалась на всех исследованных слоях твердых растворов с максимумом на длине волны $1000 \mathrm{~nm}$. Минимальные значения 
интенсивности ФЛ на этой длине волны - 600-700 в относительных единицах наблюдались на твердых растворах толщиной 50 и $1000 \mathrm{~nm}$ с максимальным рассогласованием параметра решетки относительно InP $-1.5 \cdot 10^{-2}$. Из данных таблицы видно, что для слоев $\mathrm{c}$ рассогласованием параметра решетки относительно $\mathrm{InP}$ меньше $2 \cdot 10^{-3}$, по мере увеличения значений напряжений, сброшенных за счет формирования поверхностного рельефа, существенно, на порядки растет интенсивность ФЛ. Таким образом, хорошее согласование постоянных решетки твердого раствора и подложки в сочетании с дополнительной релаксацией напряжений путем образования поверхностного рельефа позволяют избежать спинодального распада твердого раствора заданного состава и значительно, на порядки, увеличить интенсивность фотолюминесценции твердых растворов. Разработанная технология была использована при получении лабораторных образцов преобразователей лазерного излучения на основе $\mathrm{In}_{0.8} \mathrm{Ga}_{0.2} \mathrm{As}_{0.46} \mathrm{P}_{0.54} / \mathrm{InP}$-гетероструктур.

\section{Список литературы}

[1] Крохин О.Н. // УФН. 2006. Т. 176. № 4. С. 441-444.

[2] Hecht J. // New Scientist. 2010. V. 207. P. 25.

[3] 3.http://www.lasermotive.com

[4] Вавилова Л.С., Капитонов В.А., Мурашова А.В., Тарасов И.С. // ФТП. 2000. T. 34. C. 1307.

[5] Asomoza R., Elyukhin V.A. // J. Cryst. Growth. 2001. V. 222. P. 58-63.

[6] Schlenker D., Miyamoto T. // Jpn. J. Appl. Phys. 2000. V. 39. P. 5751-5757.

[7] Onabe K. // Jpn. J. Appl. Phys. 1982. V. 21. N 5. P. 797-798.

[8] Marichev A.E., Pushnyi B.V., Levin R.V. // J. Phys.: Conf. Ser. 2016. V. 690. P. 012010.

[9] Левин Р.В., Маричев А.Е., Швари, М.3. и др. // ФТП. 2015. Т. 49. В. 5. C. $715-719$.

[10] Hull R., Gray J., Wu C.C. et al. // J. Phys.: Cond. Matter. 2002. V. 14. P. 12829 12841.

[11] Гегузин Я.Е. Диффузионная зона. М.: Наука, 1979. 343 с.

Письма в ЖТФ, 2017, том 43, вып. 2 